\title{
ADAPTIVE RESPONSES TO SALINITY: SEED GERMINATION TRAITS OF SONNERATIA APETALA ALONG SALINITY GRADIENT IN SUNDARBANS, BANGLADESH
}

\author{
Nasrin $\mathbf{S}^{1}$, Mahmood $\mathbf{H}^{1, *}$, Siddique $\mathrm{MRH}^{1}$ \& Masudur $\mathrm{MR}^{2}$ \\ ${ }^{1}$ Forestry and Wood Technology Discipline, Khulna University, Khulna - 9208, Bangladesh \\ ${ }^{2}$ Mangrove Silviculture Division, Bangladesh Forest Research Institute, Forest Institute Road, Sholoshohar, Chattogram - \\ 4000, Bangladesh \\ *mahmoodhossain@hotmail.com
}

Submitted May 2019, accepted August 2019

\begin{abstract}
Water and soil salinity of the Sundarbans are increasing due to continuous reduction in fresh water flow from upstream and noticeable change in rainfall pattern. Sonneratia apetala is an important tree species for coastal afforestation in Bangladesh. It was hypothesised that $S$. apetala may show adaptive responses to salinity gradient in terms of morphological and physiological traits. This study examined the adaptive responses of $S$. apetala, growing in three saline zones (less, moderate and high) of the Sundarbans, in terms of fruit weight and seed germination traits. The fruits of less saline zone was comparatively heavier $(9.09 \pm 0.08 \mathrm{~g})$ than moderate and high saline zone. The final germination percentage (FGP), germination initiation time (GIT) and germination index (GI) of S. apetala seeds varied significantly (ANOVA, $\mathrm{p}<0.05)$ among the saline zones and saline treatments. The FGP and GI showed a significant $(\mathrm{p}<0.05)$ negative correlation with salinity levels. While, GIT showed a significant $(\mathrm{p}<0.05)$ positive correlation with salinity treatments. Seeds of moderate and high saline zones germinated faster and vigorously than the seeds of low saline zone at higher salinity levels.
\end{abstract}

Keywords: Adaptation, germination traits, Sonneratia apetala, Sundarbans, salinity

\section{INTRODUCTION}

Mangroves is one of the productive ecosystems in the tropical and sub-tropical coastal zones of the world with fluctuating tidal and saline regimes (Mattes \& Kapetsky 1988). Mangroves play a vital role in supporting food webs and nutrient cycles in the adjacent coastal ecosystems (Alongi et al. 2000, Machiwa \& Hallberg 2002, Mumby et al. 2004, Mahmood et al. 2008). About $75 \%$ of the world's tropical coastline was dominated by mangroves during the 1900's, which has been significantly reduced due to natural and humaninduced stresses (López-Portillo et al. 2017). Salinity is an important factor that controls seed germination and survival of seedling, its growth and development, and distribution of mangrove plant species (Waisel 1972, Mahmood et al. 2014). Salinity can influence the morphology and physiology of mangrove plants (Ball \& Pidsely 1995). High salinity induces high osmotic potential and ion toxicity, restricting water availability to seeds, which in turn affects imbibition, enzyme activity and cell division, thereby delaying growth initiation (Waisel 1972,
Atak et al. 2006, Kim et al. 2013). However, some mangrove species showed adaptive responses in seed germination with increased salinity (Bhosale \& Sinde 1983, Alam et al. 2018).

Increasing salinity in the coastal areas and the Sundarbans of Bangladesh is a threat to floral diversity (Siddiqi 2001, Kathiresan \& Arif 2006). Reduced flow of fresh water from upstream, change in rainfall pattern and sea level rise are the major causes of salinity increase in coastal areas and the Sundarbans of Bangladesh (Gopal \& Chauhan 2006). Three major distributaries (Gouri, Kapatakkah and Baleshwari rivers) of the Ganges are responsible for fresh water flow to the Sundarbans. Presently, the Baleshwari River is the only source of fresh water flow to the Sundarbans, and the amount has dropped from $3700 \mathrm{~m}^{3} \mathrm{~S}^{-1}$ to $364 \mathrm{~m}^{3} \mathrm{~S}^{-1}$ after the construction of Farakka dam in India during 1974 (Wahid et al. 2007). In addition, the rate of sea level rise in the coast of Bangladesh is about 6-20 $\mathrm{mm} \mathrm{yr}^{-1}$, which has accelerated saline intrusion in the coastal areas of Bangladesh 
(Karim \& Mimura 2008). Therefore, increasing salinity in the coastal zone may create a challenge to select suitable mangrove species for future plantation in the newly accreted lands and offshore island in the Bay of Bengal. Avicennia officinalis, Excoecaria agallocha, Sonneratia apetala and $S$. caseolaris were planted for coastal afforestation in Bangladesh. Sonneratia apetala grows along a salinity gradient (less, moderate and high) in the Sundarbans of Bangladesh and this species has appeared as a principal species in coastal afforestation programme due to its higher survival and growth performance (Mahmood 2015, Islam et al. 2016). It can be hypothesised that $S$. apetala may show adaptive responses to salinity gradient in terms of morphological and physiological traits. Therefore, the objectives of the present study were i) to evaluate the adaptive response to salinity in terms of fruit weight of $S$. apetala that grows in less, moderate and high saline zones of the Sundarbans, and ii) to examine the adaptive response to salinity in terms of seed germination traits of $S$. apetala that grows in different saline zones of the Sundarbans under varying saline treatments. The outcome of this study will be helpful in understanding the fate of this species by the changing salinity, as well as identifying and selecting salt-tolerant population(s) in the Sundarbans of Bangladesh.

\section{MATERIALS AND METHODS}

\section{Study site}

The Sundarbans is the world largest single tract mangrove forest, situated at the southwest corner of Bangladesh in between $21^{\circ} 30^{\prime}$ to $22^{\circ} 30^{\prime} \mathrm{N}$ and $88^{\circ} 10^{\prime}$ to $89^{\circ} 51^{\prime} \mathrm{E}$ (Figure 1) (Chaffey et al. 1985). The Sundarbans is a unique habitat for diversified flora and fauna and it contains almost $50 \%$ of mangrove flora of the world. There are 334 species of plants, 49 species of mammals, 315 species of birds, 400 species of fish and 53 species of reptiles in the Sundarbans (Karim 1995). It is a natural home for Panthera tigris and Axis axis (Moss 1993). However, the major tree species

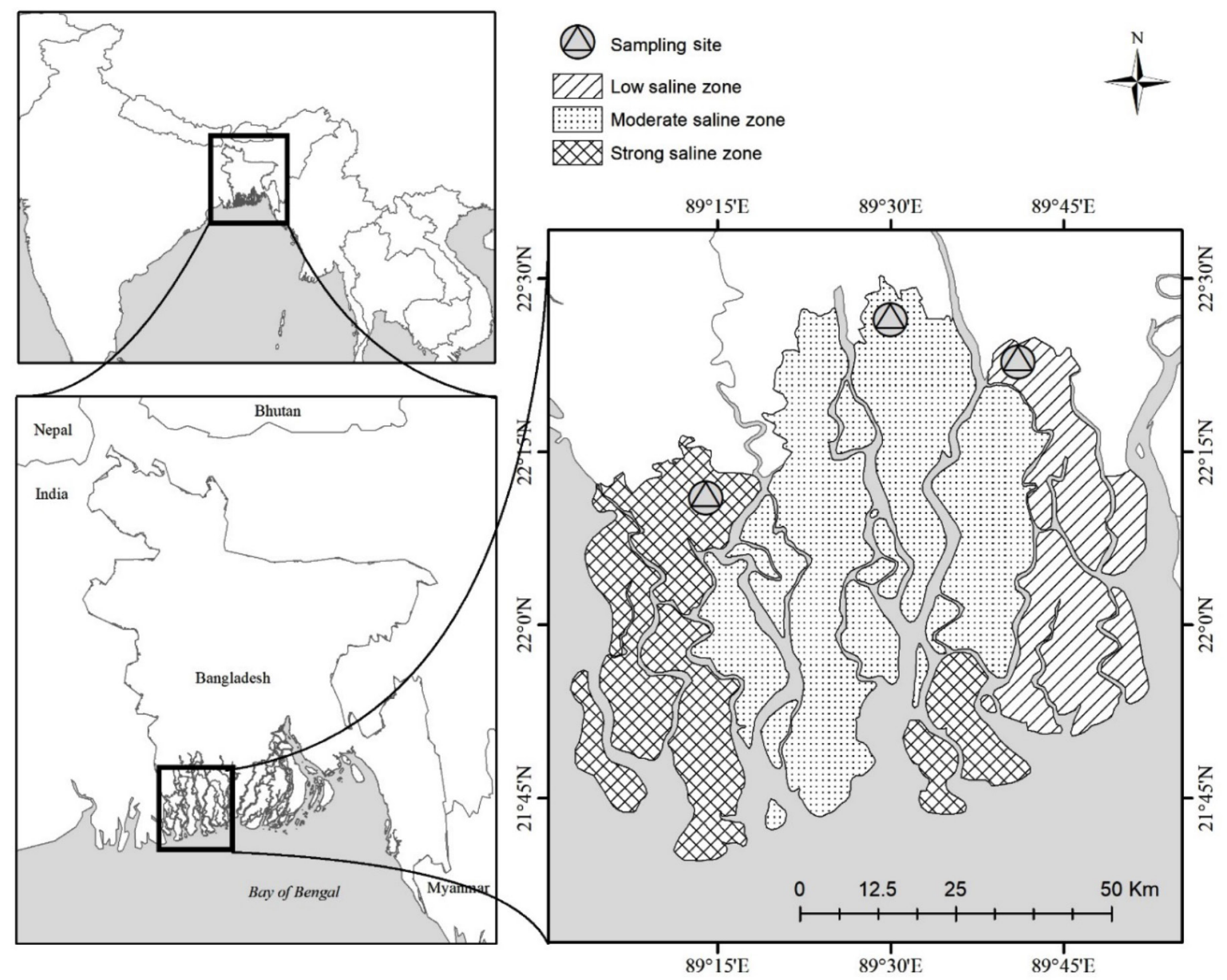

Figure 1 Map showing study area in the Sundarbans mangrove forest of Bangladesh 
of the Sundarbans are Heritiera fomes, Excoecaria agallocha, Ceriops decandra, Avicennia officinalis, Sonneratia apelala, S. caseolaris, Bruguiera sexangula, Xylocarpus molucensis, X. gratatum, Rhizophora apicilata and $R$. mucronata. Besides these, there are different species of phytoplankton, bacteria, fungi and many other microorganisms (Mahmood 2015). Based on salinity (practical salinity unit, psu), this forest is divided into low ( 0.5 to $5 \mathrm{psu}$ ), moderate ( 5 to $18 \mathrm{psu}$ ) and high or strong (18 to $30 \mathrm{psu}$ ) saline zones (Siddiqi 2001). The climate is strongly seasonal with $87 \%$ of the mean annual precipitation $(1,500 \mathrm{~mm})$ occurring between May and October, and the remaining months are considered as dry season with no or less precipitation. The range of maximum and minimum temperatures are 18 to $35^{\circ} \mathrm{C}$ in the summer and 12 to $29^{\circ} \mathrm{C}$ during the winter. Soil is silty clay, in situ $\mathrm{pH}$ is neutral to alkaline and range of organic carbon is 1.5 to $3 \%$ (Mahmood 2015).

\section{Fruit collection}

The bulk of $S$. apetala mature fruits were collected from the pure patch of the species, located in the three saline zones of the Sundarbans. The locations of the pure patch were identified using the vegetation map derived by Chaffey et al. (1985), which was further confirmed by field visits. Fruits were collected from 15 selected mother trees (DBH $>40 \mathrm{~cm}$, height $>10 \mathrm{~m}$, straight bole without broken top and unaffected by disease) for each saline zone: less $\left(89^{\circ} 41^{\prime} \mathrm{E}\right.$ and $\left.22^{\circ} 22^{\prime} \mathrm{N}\right)$, moderate $\left(89^{\circ} 29^{\prime} \mathrm{E}\right.$ and $\left.22^{\circ} 26^{\prime} \mathrm{N}\right)$ and high $\left(89^{\circ} 14^{\prime} \mathrm{E}\right.$ and $\left.22^{\circ} 10^{\prime} \mathrm{N}\right)$ (Figure 1$)$.

\section{Phenology and fruit weight}

Phenology of S. apetala varies with site conditions (Islam \& Siddiqi 1987). The flowering and fruiting seasons of this species are April to June and June to September, respectively (Das \& Siddiqi 1985, Mahmood 2015). The collected fruits from low ( 0.5 to $5 \mathrm{psu}$ ), moderate ( 5 to $18 \mathrm{psu}$ ) and high (18 to $30 \mathrm{psu}$ ) saline zones were sorted manually to discard the defective ones. One hundred randomly selected, defect free fruits constituted a sample. Thus, three samples of fruits $(100 * 3=300$ fruits $)$ were collected from each saline zone to obtain zone wise fruit weight. The fruit of $S$. apetala is round in shape, hence, length and width were not measured.

\section{Germination experiment}

The sorted fruits of each saline zone were stacked separately and covered superlatively with straw for 4-5 days, and watered daily to partially decompose. The partial decomposed fruits were then washed to get the seeds. Seed germination experiment was conducted according to Alam et al. (2018). In this experiment, seeds were laid in a randomised block design with eight treatments of salinity $(0,5,10,15,20,25,30$ and $35 \mathrm{psu})$ and three replications for each saline zone. Twentyfour ( 8 treatments $\times 3$ replications) germination trays $(75 \times 75 \times 6 \mathrm{~cm})$ were prepared for each saline zone. Trays were filled with $3 \mathrm{~cm}$ thick layer of coarse sand, and one hundred seeds were sown in each tray. A total of 2400 seeds ( 8 treatments $\times 3$ replications $\times 100$ seeds) were used for the germination experiment for each saline zone. The experiment was conducted in a forest nursery glass house of Khulna University.

Crude sea salt (unrefined sea salt containing all chemical constituents) was used for preparing salinity treatments of $5,10,15,20,25,30$ and 35 psu. Distilled water was used for 0 psu treatment. Water solution of appropriate salinity treatment was added to the respective germination trays until the sand became saturated and a thin film of water was conspicuous. Water and salinity levels of each tray were checked daily and adjusted as required. The range of daily maximum temperature and relative humidity during the experimental period were recorded as 31 to $35{ }^{\circ} \mathrm{C}$ and 64 to $75 \%$, respectively. Germination was defined as the initiation of the first root, and the seedlings were removed from the trays immediately after germination. The number of germinated seeds were counted and recorded at 24-hour intervals for four weeks.

\section{Germination traits}

Final germination percentage (FGP) is the percentage of sown seeds that germinated at the end of the experiment:

FGP $=$ (Number of germinated seeds $/$ total number of sown seeds) $\times 100$

Germination initiation time (GIT) is the time required to initiate germination of seeds:

GIT = Day of first germination - day of seed soing (Ellis \& Roberts 1981) 
Germination index (GI) is calculated to find out vigorous seed. It is a good indicator of dormancy decay; higher value of GI indicates good quality of seeds.

$$
\mathrm{GI}=\sum \mathrm{n} / \mathrm{d},
$$

where $\mathrm{n}=$ number of seedling emerging in a day and $d=$ the day after seed sowing (Karaguzel et al. 2004).

FGP, GI and GIT were calculated for seeds of all saline zones and salinity treatments.

\section{Statistical analysis}

One-way analysis of variance (ANOVA) was performed to compare the fruit weights of different saline zones. Two way ANOVA was also conducted for FGP, GIT and GI values of different salinity treatments and zones to understand the influence of salinity on germination traits. The SAS statistical software (ver. 6.12) was used for ANOVA analysis. Pearson correlation analysis was conducted among germination parameters (FGP, GI and GIT), and salinity treatments using IBM SPSS statistical software (ver. 20) to evaluate the relationship among salinity treatments and seed germination parameters. Bonferroni adjustment analysis was also performed as post-ANOVA tests for pairwise comparisons among the germination parameters (FGP, GIT and GI) for all zones and salinity treatments using IBM SPSS (ver. 20) statistical software.

\section{RESULTS}

\section{Fruit weight}

Comparatively $(\mathrm{p}<0.05)$ higher weight $(9.09$ $\pm 0.08 \mathrm{~g}$ ) was observed in the less saline zone and lowest weight $(6.10 \pm 0.18 \mathrm{~g})$ in the high saline zone (Figure 2). Moreover, fruit weights significantly $(\mathrm{p}<0.05)$ varied between less saline zone (LSZ) and medium saline zone (MSZ) as well as between LSZ and high saline zone (HSZ), while fruit weight did not significantly $(p>0.05)$ vary between MSZ and HSZ.

\section{Germination traits}

The FGP of seeds varied significantly $(p<0.05)$ among the salinity treatments and among the saline zones. The FGP showed significant

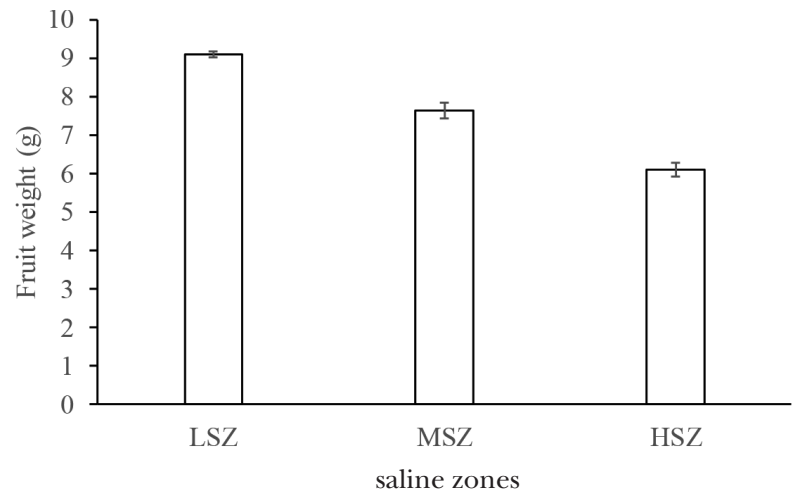

Figure 2 Fruit morphology (fruit weight) from three different saline zones; LSZ = less saline zone, $\mathrm{MSZ}=$ medium saline zone, $\mathrm{HSZ}=$ high saline zone

negative correlation $(\mathrm{p}<0.05, \mathrm{r}=-0.81)$ with the salinity treatments (Table 1). The FGP of seeds for LSZ was lowest (28.33\%) compared with seeds of MSZ (49.67\%) and HSZ (59.67\%), at the higher salinity treatments of 35 psu (Figure 3a). Bonferroni adjustment analysis showed no significant $(p>0.05)$ differences in FGP among saline zones at 0 to 15 psu salinity treatments. However, at 20 to 35 psu salinity treatments, the differences in FGP between LSZ and MSZ, and between LSZ and HSZ were significant $(p<0.05)$, while the differences in FGP between MSZ and HSZ was not significant $(\mathrm{p}>0.05)$ (Table 2$)$.

The GIT was found to vary significantly $(\mathrm{p}<$ $0.05)$ among salinity treatments and zones. The GIT showed a significant positive correlation $(\mathrm{p}<0.05, \mathrm{r}=0.87)$ with salinity treatments (Table $1)$. The lowest GIT (2 days) was observed at 0 psu for seeds of all saline zones. But, highest GIT ( 8 days) was observed at 35 psu salinity treatment for LSZ followed by MSZ and HSZ (Figure 3c). Bonferroni adjustment analysis showed no significant $(p>0.05)$ differences in GIT among the saline zones at 0 to 15 psu salinity treatments. However, at 20 to 35 psu salinity treatments, GIT was found to vary significantly $(\mathrm{p}<0.05)$ between LSZ and MSZ, and between LSZ and HSZ, while GIT between MSZ and HSZ did not vary significantly $(p>0.05)$ (Table 2$)$.

The GI was found to vary significantly $(\mathrm{p}<$ $0.05)$ among saline treatments and zones. The GI showed a significant negative correlation ( $\mathrm{p}$ $<0.05, \mathrm{r}=-0.91$ ) with salinity treatments (Table $1)$. Highest GI of seeds $\left(18.87 \pm 0.62\right.$ seed day $\left.^{-1}\right)$ was observed for HSZ at 0 psu treatment, however GI was found to decrease with increasing salinity 
Table 1 Correlation matrix of all studied parameters of germination traits

\begin{tabular}{lcccc}
\hline & Salinity & FGP & GIT & GI \\
\hline Salinity & 1 & & & \\
Final germination percentage (FGP) & $-0.81^{*}$ & 1 & & \\
Germination initiation time (GIT) & $0.87^{*}$ & $-0.76^{*}$ & 1 & \\
Germination index (GI) & $-0.91^{*}$ & $0.84^{*}$ & $-0.90^{*}$ & 1 \\
\hline
\end{tabular}

* Significant at the 0.05 level

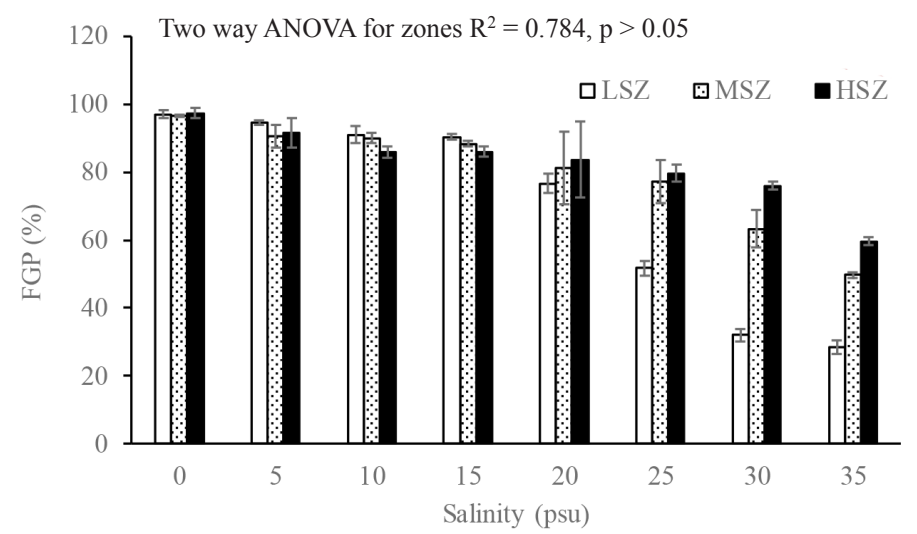

LSZ = less saline zone

MSZ $=$ medium saline zone

$\mathrm{HSZ}=$ high saline zone

(a)

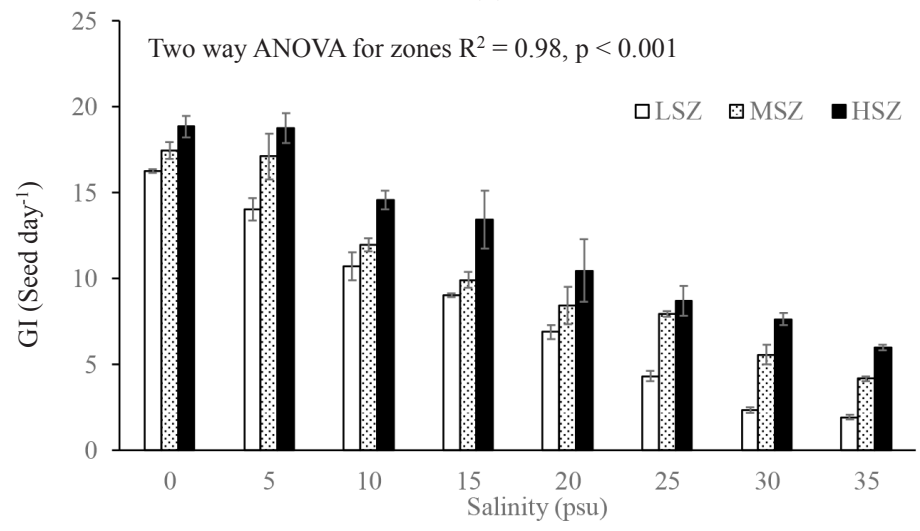

Two way ANOVA for salinity treatment: $\mathrm{R}^{2}=0.94, \mathrm{p}<0.001$

(b)

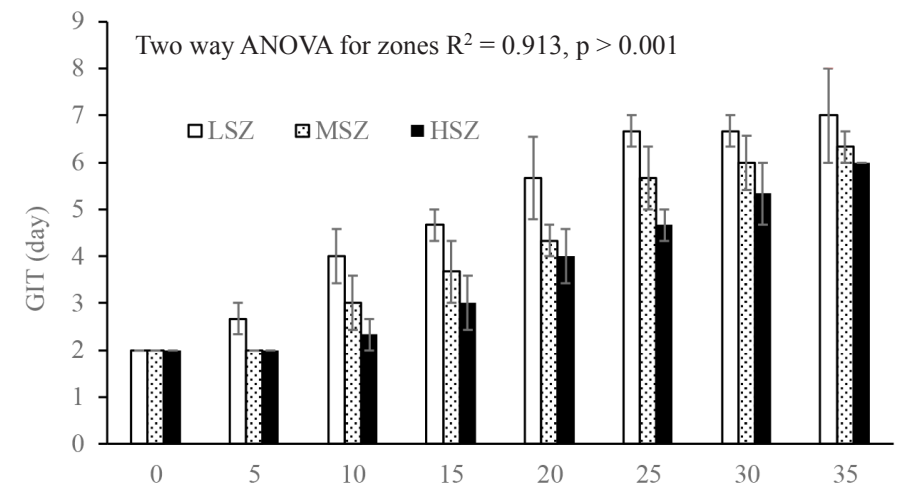

Two way ANOVA for salinity treatment: $\mathrm{R}^{2}=0.972 \mathrm{p}<0.001$

(c)

Figure 3 Germination traits of Sonneratia apetala (a) final germination percentage (FGP), (b) germination index time (GIT), (c) germination index (GI) at different salinity levels with three saline zones; means are significantly different as determined by two way ANOVA; vertical bars show standard errors of mean 
Table 2 Pairwise comparisons (LSD) with Bonferroni adjustment results between different saline zones in respect of final germination percentage (FGP), germination initiation time (GIT) and germination index $(\mathrm{GI})$

\begin{tabular}{|c|c|c|c|c|}
\hline Salinity & Between zones & FGP & GIT & GI \\
\hline \multirow{3}{*}{0} & LSZ and MSZ & 0.98 & 1.00 & 1.00 \\
\hline & LSZ and HSZ & 0.99 & 1.00 & 1.00 \\
\hline & MSZ and HSZ & 0.95 & 1.00 & 0.69 \\
\hline \multirow{3}{*}{5} & LSZ and MSZ & 0.98 & 0.15 & 0.21 \\
\hline & LSZ and HSZ & 1.00 & 0.15 & 0.04 \\
\hline & MSZ and HSZ & 0.79 & 1.00 & 0.84 \\
\hline \multirow{3}{*}{10} & LSZ and MSZ & 1.00 & 0.64 & 0.56 \\
\hline & LSZ and HSZ & 0.57 & 0.18 & 0.05 \\
\hline & MSZ and HSZ & 0.60 & 1.00 & 0.07 \\
\hline \multirow{3}{*}{15} & LSZ and MSZ & 0.78 & 0.73 & 0.06 \\
\hline & LSZ and HSZ & 0.10 & 0.22 & 1.00 \\
\hline & MSZ and HSZ & 0.60 & 1.00 & 0.14 \\
\hline \multirow{3}{*}{20} & LSZ and MSZ & $0.43^{*}$ & $0.03^{*}$ & $0.01 *$ \\
\hline & LSZ and HSZ & $0.06^{*}$ & $0.01 *$ & $0.04^{*}$ \\
\hline & MSZ and HSZ & 0.49 & 1.00 & 0.90 \\
\hline \multirow{3}{*}{25} & LSZ and MSZ & $0.01 *$ & $0.01^{*}$ & $0.01 *$ \\
\hline & LSZ and HSZ & $0.01 *$ & $0.01 *$ & $0.01 *$ \\
\hline & MSZ and HSZ & 0.87 & 0.55 & 1.00 \\
\hline \multirow{3}{*}{30} & LSZ and MSZ & $0.00^{*}$ & $0.01^{*}$ & $0.01 *$ \\
\hline & LSZ and HSZ & $0.00 *$ & $0.01 *$ & $0.00 *$ \\
\hline & MSZ and HSZ & 0.07 & 0.25 & 0.08 \\
\hline \multirow{3}{*}{35} & LSZ and MSZ & $0.00^{*}$ & $0.00^{*}$ & $0.00 *$ \\
\hline & LSZ and HSZ & $0.00 *$ & $0.01 *$ & $0.00 *$ \\
\hline & MSZ and HSZ & 0.06 & 0.24 & 0.80 \\
\hline
\end{tabular}

* Significant at 0.05 level; LSZ = less saline zone, MSZ = medium saline zone, HSZ = high saline zone

treatments for all zones. However, lowest (1.92 \pm 0.11 ) GI was observed for LSZ at 35 psu salinity (Figure $3 \mathrm{~b}$ ). Bonferroni adjustment analysis showed no significant $(p>0.05)$ differences in GI among the saline zones at 0 to 15 psu salinity treatments. However, at 20 to 35 psu salinity levels, the differences in GI between LSZ and MSZ, and between LSZ and HSZ were significant $(p<0.05)$, while GI between MSZ and HSZ did not vary significantly $(p>0.05)$ (Table 2$)$.

\section{DISCUSSION}

Sonneratia apetala fruits of HSZ of the Sundarbans were lighter than the fruits of LSZ and MSZ. Similar findings were also observed by Alam et al. (2018) while working with A. officinalis of the Sundarbans. Higher salt stress may reduce $\mathrm{CO}_{2}$ assimilation, inhibiting photosynthesis which affects the energy source for growth and development (Naidoo 1987, Lin \& Sternberg 1992, Siddiqi 2001). In other ways, most of the acquired energy was invested to fight against saline condition e.g. desalinisation and water uptake against an osmotic gradient (Waisel 1972). Salinity exerts complex effects on plants through ionic, osmotic and nutritional interactions (Zhu 2010, Liu et al. 2015). Salinity and other environmental factors also induce changes in the anatomy and morphology of mangrove plants, which may result in inter- and intra-specific variability among mangroves (Kathiresan \& 
Bingham 2001, Alam et al. 2019). These changes are considered as adaptive responses that may increase the survival chances of mangroves and endure salinity stress (Zhu 2001, Alam et al. 2018).

The FGP and GI (germination vigorousness) were lower at higher salinity levels. There was no significant differences in final germination percentage up to 15 psu among the three saline zones. The highest germination at $0 \mathrm{psu}$, irrespective of saline zones, indicated the facultative nature of $S$. apetala. At and above 20 psu salinity, the FGP were higher for MSZ and HSZ, showing adaptive responses to higher saline environments as stated by Waisel (1972) and Alam et al. (2018). This phenomenon explains the potentiality of a population to adopt with environmental conditions, especially with high salinity level (Nasrin et al. 2019). Increased salinity creates high osmotic potential in the germination medium, affecting imbibition and potentially inducing $\mathrm{Na}$ ion toxicity in seeds, and influencing enzyme activity and cell division (Waisel 1972, Clough 1984, Atak et al. 2006, Kim et al. 2013). These inhibitory effects may be responsible for the increased GIT, and decreased FGP and GI of S. apetala seeds. Similar observation was reported by Mahmood et al. (2014) with different mangrove species $(H$. fomes, X. mekongensis, X. granatuma and Aglaia cucullatta), and Alam et al. (2018) for A. officinalis.

In the germination experiment, seeds of different saline zones displayed variation in germination traits among the saline treatments. This may arise from acclimatisation of the plants to local environmental conditions (Vandelook et al. 2008) . Johnson et al. (1992) demonstrated that species exposed to stressful environmental conditions were physiologically more adaptive to the stressful conditions than species from lessstressful environments. Variations in geographical condition lead to the evolution of different adaptations to the local environment (Savolainen et al. 2007). This type of adaptive responses may help to tolerate the heterogeneous environments across the distribution of a species (Liu et al. 2015).

\section{CONCLUSION}

The fruits of S. apetala that grow in LSZ were much heavier than MSZ and HSZ. Seed germination traits of this species in terms of FGI, GI and GIT varied among salinity treatments and origin of seeds. Faster and vigorous germination of seeds originated from MSZ and HSZ compared to those from LSZ, at higher saline treatments. This phenomenon indicated that seeds of MSZ and HSZ may have more inherent capacity to adapt with high saline conditions during their germination process. Local environmental variation (i.e salinity gradient of the Sundarbans) may have potential influences on the adaptive population of $S$. apetala in MSZ and HSZ of the Sundarbans.

\section{ACKNOWLEDGEMENT}

The authors would like to acknowledge the financial support provided by Research Grants Program (RGP), Khulna University Research Cell, Khulna University. The authors also appreciate the technical support from Forestry and Wood Technology Discipline, Khulna University, Bangladesh.

\section{REFERENCES}

Alam MR, Mahmood H \& Rahman MM. 2019. Physiologically adaptive plasticity in nutrient resorption efficiency of Avicennia officinalis L. under fluctuating saline environments in the Sundarbans of Bangladesh. Hydrobiologia 828: 41-56.

Alam RMD, Mahmood H, Khusi MSTLR \& Rahman MMD. 2018. Adaptive phenotypic plasticity of Avicennia officinalis L. across the salinity gradient in the Sundarbans of Bangladesh. Hydrobiologia 808: 163-174.

Alongi DM, Tirendi F \& Clough BF. 2000. Below-ground decomposition of organic matter in forests of the mangroves Rhizophora stylosa and Avicennia marina along the arid coast of Western Australia. Aquatic Botany 68: 97-122.

Atak M, Kaya MD, Kaya G, Cikili Y \& Ciftci CY. 2006. Effects of $\mathrm{NaCl}$ on the germination, seedling growth and water uptake of triticale. Turkish Journal of Agriculture and Forestry 30: 39-47.

Ball MC \& Pidsley SM. 1995. Growth responses to salinity in relation to distribution of two mangrove species, Sonneratia alba and S. lanceolata, in Northern Australia. Functional Ecology 9: 77-85.

Bhosale LJ \& Shinde LS. (1983) Photosynthetic products and enzymes in a mangrove, Aegiceras corniculatum (L.) Blanco and halophyte, Sesuvium portulacastrum L. Photosynthetica 7: 59-63.

ChafFey DR, MilLer FR \& SANDOM KH. 1985. A Forest Inventory of the Sundarbans, Bangladesh. Land Resources Development Centre, Surrey.

CLOugh BF. 1984. Growth and salt balance of the mangroves Avicennia marina and Rhizophora stylosa in relation to salinity. Australian Journal of Plant Physiology 11: 419-430. 
DAS S \& Siddiei NA. 1985. The Mangrove and Mangrove Forests of Bangladesh. Mangrove Silviculture Division. Bulletin Number 2. BFRI and UNDP/FAO project, BGD/79/017, Chittagong.

Ellis RA \& Roberts EH. 1981. The Quantification of Ageing and Survival in Orthodox Seeds. Seed Science Technology 9: 373-409.

Gopal B \& ChauHan M. 2006. Biodiversity and its conservation in the Sundarbans mangrove ecosystem. Aqua Science 68: 338-354.

ISLAM MR \& SIDDIQI NA. 1987. Seed requirement and method of sowing of Keora (Sonneratia apetala Buch.-Ham.) seeds in the nursery. Bano Biggyan Patrika 16: 73-79.

Islam SA, MiaH MAQ, HabiB MA \& AlAm MM. 2016. Growth and yield of Sonneratia apetala (Keora) plantations raised from different seed sources in the central coastal belt of Bangladesh. Journal of Bioscience and Agriculture Research 6: 565-569.

Johnson DW, Smith SE \& Dobrenz AK. 1992. Selection for increased forage yield in alfalfa at different $\mathrm{NaCl}$ levels. Euphytica 60: 27-35.

Karaguzel O, Cakmakci S, Ortacesme V \& Aydinoglu B. 2004. Influence of seed coat treatments on germination and early seedling growth of Lupinusvarius L. Pakistan Journal of Botany 36: 65-74.

Karim A. 1995. Draft Report on Mangrove Silviculture. Volume 1, Integrated Resource Development of the Sundarbans Reserved Forest. FAO/ UNDP Project, BGD/86/056, Chittagong.

Karim M \& Mimura N. 2008. Impacts of climate change and sea-level rise on cyclonic storm surge floods in Bangladesh. Global Environmental Change 18: 490-500.

KathiResan K \& Bingham BL. 2001. Biology of mangroves \& mangrove ecosystem. Advances in Marine Biology 40: 81-251.

KATHIRESAN K \& ARIF MF. 2006. Managing Sundarbans for uncertainty and sustainability. Pp 1-31 in Duke NC (ed) International Conference and Exhibition on Mangroves of Indian and Western Pacific Oceans. ICEMAN, Kuala Lumpur.

Kim W, Lee Y, Park J, Lee N \& Choi G. 2013. Honsu a protein phosphatase $2 \mathrm{C}$, regulates seed dormancy by inhibiting ABA signaling in Arabidopsis. Plant Cell Physiology 54: 555-572.

Lin G \& Sternberg LDASL. 1992. Effects of growth form, salinity, nutrient and sulphide on photosynthesis, carbon isotope discrimination and growth of red mangrove (Rhizophora mangle L.). Australian Journal of Plant Physiology 19: 509-517.

LiU YJ, Zhang LR, Xu XL \& NiU HS. 2015. Understanding the wide geographic range of a clonal perennial grass: plasticity versus local adaptation. AoB Plants 7: 141.

López-Portillo J, Lewis III RR, SAenger P et al. 2017. Mangrove forest restoration and rehabilitation. Pp 301-346 in Rivera-Monroy VH et al. (eds.) Mangrove Ecosystems: A Global Biogeographic Perspective, Structure, Function, and Services. Springer Nature, Switzerland.

Machiwa JF \& Hallberg RO. 2002. An empirical model of the fate of organic carbon in a mangrove forest partly affected by anthropogenic activity. Ecological Modelling 47: 69-83.

Mahmood H, Saberi O, Japar Sidik B \& Misri K. 2008. Net primary productivity of Bruguiera parviflora (Wight \& Arn.) dominated mangrove forest at Kuala Selangor, Malaysia. Forest Ecology and Management 255: 179-182.

Mahmood H, Saha S, Salakin S, Al-Mamun A, Siddigue MRH \& ABDUllaH SMR. 2014. Salinity influence on germination of four important mangrove species of the Sundarbans, Bangladesh. Agriculture and Forestry 60: $125-135$.

MaHmOOD H. 2015. Handbook of Selected Plant and Species of The Sundarbans and The Embankment Ecosystem. Sustainable development and biodiversity conservation in coastal protection forests, Bangladesh (SDBC-Sundarbans) - project implemented by the DEeutsche Gesellschaft fur Internationale zusammenarbeit (GIZ) GmbH. German Federal Ministry for Economic Cooperation and Development (BMZ), Dhaka.

Mattes H \& Kapetsky SS. 1988. World-Wide Compendium of Mangrove-Associated Aquatic Species of Economic Importance. FAO Fisheries CIC Number 814, Rome.

Moss PDV. 1993. Final Report on Tourism and Recreation, Integrated Resource Development of the Sundarbans Reserve Forest, Bangladesh. FAO/ UNDP Project, BGD/84/056, Chittagong.

Mumby PJ, Edwards AJ, Arias-Gonzalez JE et al. 2004. Mangroves enhance the biomass of coral reef fish communities in the Caribbean. Nature 427: 533-536.

NAIDOo G. 1987. Effects of salinity and nitrogen on growth and plant water relations in the mangrove, Avicennia marina (Forsk.) Vierh. New Phytologist 107: 317-326.

Nasrin S, Mahmood H \& Rahman MM. 2019. Adaptive responses to salinity: nutrient resorption efficiency of Sonneratia apetala (Buch.-Ham.) along the salinity gradient in the Sundarbans of Bangladesh. Wetlands Ecology and Management 27: 343-351.

Savolainen O, Pyhajarvi T \& Knurr T. 2007. Gene flow and local adaptation in trees. Annual Review of Ecology, Evolution and Systematics 38: 595-619.

SIDDIQI NA. 2001. Mangrove Forestry in Bangladesh. Institute of Forestry and Environmental Science, University of Chittagong, Chittagong.

Vandelook F, Van De Moer D \& Van Assche JA. 2008. Environmental signals for seed germination reflect habitat adaptations in four temperate Caryophyllaceae. Functional Ecology 22: 470-478.

WAHId SM, BABEL MS \& Bhuiyan AR. 2007. Hydrologic monitoring and analysis in the Sundarbans mangrove ecosystem, Bangladesh. Journal of Hydrology 332: 381-395.

Waisel Y. 1972. Biology of Halophytes. Academic Press, New York and London.

Zhu JK. 2001. Plant salt tolerance. Trends in Plant Science 6: $66-71$.

ZHU JK. 2010. Genetic analysis of plant salt tolerance using Arabidopsis. Plant Physiology 124: 941-948. 